\title{
Burnout Contagion in Supervisor-Subordinate Dyads
}

\author{
Cody Logan Chullen ${ }^{1}$ \\ ${ }^{1}$ Department of Management, College of Business, East Carolina University, Greenville, NC, USA \\ Correspondence: Cody Logan Chullen, Department of Management, College of Business, East Carolina University, \\ Greenville, NC 27858, USA. Tel: 1-252-737-4608, E-mail:chullenc@ecu.edu
}

Received: May 18, 2014

Accepted: May 26, 2014

Online Published: May 27, 2014

doi:10.5430/bmr.v3n2p67

URL: http://dx.doi.org/10.5430/bmr.v3n2p67

\begin{abstract}
Employee burnout has an extensive history in applied psychology, with decades of research and hundreds of studies examining both its antecedents and consequences. Despite these advancements, and although theoretical models of burnout have cited the importance of supervisory behavior as a factor contributing to the deleterious effects of organizational role stressors, little empirical research has systematically measured supervisory burnout in relation to subordinate burnout. Without a thorough understanding of the relationship between supervisor and subordinate burnout organizations may struggle to properly develop intervention strategies aimed at reducing and eliminating burnout within the workforce. Drawing on emotional contagion theory and the interactional psychology framework, this study proposes and tests a model articulating the processes by which supervisor burnout leads to subordinate burnout. Utilizing a sample of 93 supervisor-subordinate dyads, results indicate that supervisor burnout influences subordinate burnout via the emotional contagion process and that subordinate susceptibility to emotional contagion serves as an important individual difference variable that moderates this relationship. Implications for theory and practice as well as future directions are discussed.
\end{abstract}

Keywords: Burnout, Supervisor, Subordinate, Emotional contagion, Personality

\section{Introduction}

Employee burnout is defined as a psychological response to work-related stress wherein employees experience emotional exhaustion, depersonalization, and reduced personal accomplishment (Maslach, 1982; Maslach, Schaufeli, \& Leiter, 2001). Emotional exhaustion refers to a "lack of energy and a feeling that one's emotional resources are used up" (Cordes \& Dougherty, 1993). Depersonalization refers to a coping mechanism whereby employees develop negative, cynical attitudes about their work and treat others around them as objects rather than people (Lee \& Ashforth, 1996). Lastly, reduced personal accomplishment refers to a "decline in feelings of competence or productivity at work" (Halbesleben \& Bowler, 2005).

Employee burnout has important implications for both individuals and organizations (Cropanzano, Rupp, \& Byrne, 2003). For individuals, burnout has been tied to numerous health related complications including anxiety, depression, and diminished psychological well-being, amongst others (Cordes \& Dougherty, 1993; Kahill, 1988; Maslach, 1982; Maslach, 1993; Shirom, Westman, Shamai, \& Carel, 1997; Wright \& Bonnet, 1997; Wright \& Hobfoll, 1994). Similarly, in the organizational context burnout has been linked to deviant behavior, turnover, decreased employee commitment, poor morale, poor quality of care in health services institutions, loss of management potential, and job dissatisfaction (Chullen, Dunford, Angermeier, Boss \& Boss, 2010; Jackson, Schwab, \& Schuler, 1986; Leiter \& Maslach, 1988; Wolpin, Burke, \& Greenglass, 1991).

Consequently, employee burnout has an extensive history in applied psychology, with decades of research and hundreds of studies examining both its antecedents and consequences (Cordes \& Dougherty, 1993; Shirom, 1989; Taris, 2006). Despite these advancements, and although theoretical models (Numerof, 1983; Perlman \& Hartman, 1982) of burnout have cited the importance of supervisory behavior as a factor contributing to the deleterious effects of organizational role stressors, little empirical research has systematically measured supervisory burnout in relation to subordinate burnout.

Understanding the effects of supervisory burnout is critical because supervisors' burnout may influence subordinates' cognitions and behaviors (George, 2000; Goleman, Boyatzis, \& McKee, 2001). As such, supervisors' burnout may ultimately impact the performance of their subordinates. The effects of supervisory burnout on subordinate burnout and the manner in which the former affects the latter are important issues that await further research. Accordingly, 
the purpose of this paper is to articulate and test a model of dyadic burnout, with a specific focus on how supervisor burnout influences subordinate burnout.

\subsection{Theory \& Hypotheses}

Emotional contagion theory (Hatfield, Cacioppo, \& Rapson, 1994) provides one conceptual lens through which the main effects of supervisor burnout on subordinate burnout may be better understood. Emotional contagion is formally defined as "The tendency to automatically mimic and synchronize facial expressions, vocalizations, postures, and movements with those of another person and, consequently, to converge emotionally" (Hatfield et al., 1994, p. 5). Research has provided preliminary empirical evidence for the emotional contagion phenomenon, indicating that teammates indeed transmit attitudes such as burnout to one another in such a manner that the team itself may become "burned out" (Bakker, Demerouti, \& Schaufeli, 2003; Bakker, LeBlanc, \& Schaufeli, 2005).

However, research has only begun to examine burnout and the emotional contagion process within a leadership context (Cherulnik, Donley, Wiewel, \& Miller, 2001; Lewis, 2000; Sy, Cote', \& Saavedra 2005). For example, in a series of controlled laboratory experiments, researchers found evidence for emotional contagion from supervisors to employees (Cherulnik et al., 2001; Halverson, Murphy, \& Riggio, 2004; Lewis, 2000; Sy et al., 2005). Because supervisors act as highly salient organizational members, it stands to reason that emotional contagion from supervisors to subordinates should be particularly strong (Connelly, Gaddis, \& Helton-Fauth, 2002). An obvious implication that may be drawn from these findings is that supervisor burnout may be an important factor directly affecting subordinate burnout.

Additionally, individual differences may impact the emotional contagion process and degree to which it occurs. Drawing on emotional contagion theory and the interactional psychology framework (Schneider, 1983), susceptibility to emotional contagion serves as an important individual difference variable that may influence the emotional contagion process between supervisor burnout and subordinate burnout. Figure 1 depicts an overall theoretical model representing all study variables and their proposed relationships.

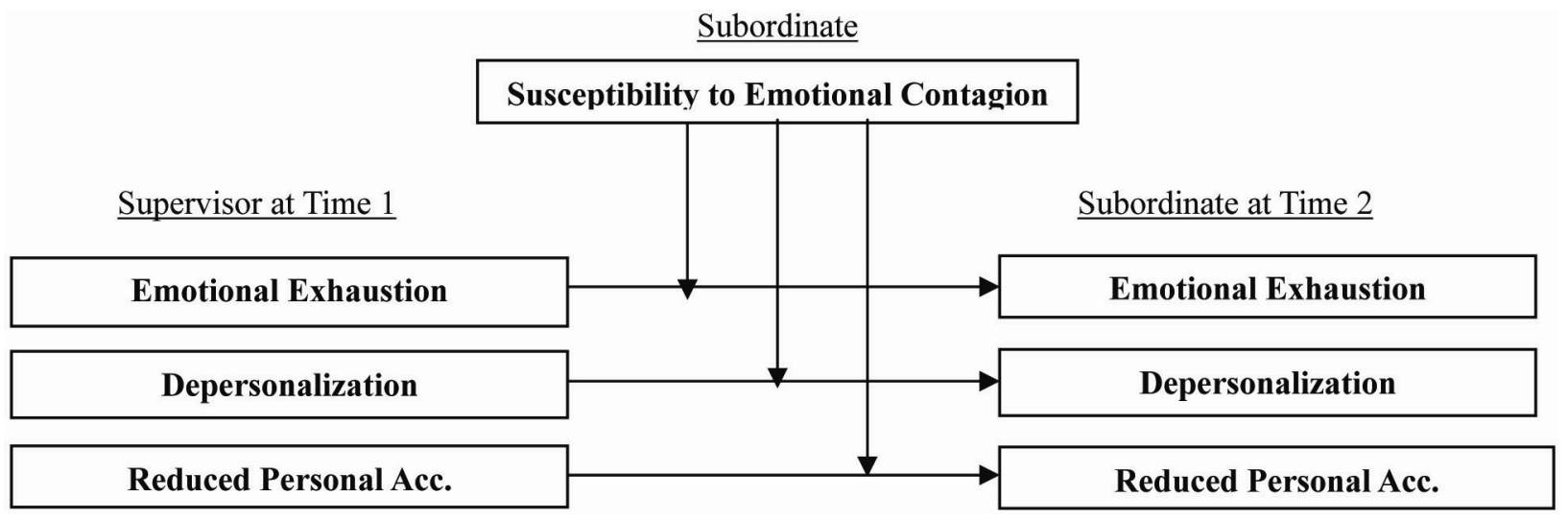

Figure 1. Overall Theoretical Model

Description: Model Depicting Burnout Contagion between Supervisor and Subordinate.

\subsection{Three Components of Burnout}

During the late 1970's and early 1980's, a series of studies (Maslach, 1982; Maslach \& Jackson, 1981; Pines, Aronson, \& Kafry, 1981) established the three-dimensional factor structure of the burnout construct. As noted above, these dimensions include emotional exhaustion, depersonalization, and reduced personal accomplishment.

Emotional exhaustion, the first component of burnout, characterized by a 'lack of energy and a feeling that one's emotional resources are used up' (Cordes \& Doughterty, 1993), and is believed to be central to the burnout experience. Often referred to as 'compassion fatigue,' emotional exhaustion is believed to result from emotionally charged interactions with others. Depersonalization refers to the development of negative, cynical attitudes (Jackson, Turner, \& Brief, 1987) about one's work, coworkers, and customers. Research suggests that employees experiencing depersonalization may withdraw from their work (Maslach \& Pines, 1977). Finally, reduced personal accomplishment refers to an individual's feelings of diminished ability in accomplishing tasks related to his or her job. Individuals experiencing reduced personal accomplishment often feel a decline in their sense of accomplishment (Leiter \& Maslach, 1988). 


\subsection{Emotional Contagion}

Emotional contagion theory (Hatfield et al., 1994) discusses one conceptual lens through which supervisor burnout may lead to change in subordinate burnout. As noted earlier, emotional contagion is formally defined as "The tendency to automatically mimic and synchronize facial expressions, vocalizations, postures, and movements with those of another person and, consequently, to converge emotionally" (Hatfield et al., 1994, p. 5). This definition emphasizes a non-conscious process whereby individuals' moods may converge. The emotional exhaustion dimension of burnout would appear to function most prominently through unconscious contagion in supervisor-subordinate dyads, because fatigue is often expressed in a physical way. Recurring exposure to emotionally exhausted supervisors' facial, vocal, and postural cues should lead to emotional convergence and consequently subordinate emotional exhaustion.

Additionally, researchers have also convincingly argued that individuals may "catch" the emotions of another via a conscious cognitive process by "tuning in" to the emotions of others (Bakker et al., 2003). In this instance, an individual may identify or empathize with another and through this process may recall similar experiences in which they felt the same way. In so doing, the individual may also feel similar emotions. Depersonalization and reduced personal accomplishment would seem most likely to function through conscious crossover. For instance, subordinates who regularly engage in discussion with supervisors high on depersonalization and/or reduced personal accomplishment about problematic experiences at work are more likely to catch their superiors' negative attitudes. This convergence results from subordinates repeatedly trying to understand their supervisor's problems, and presumably "tuning-in" to their supervisors' negative attitudes. The greater the occurrence of these occasions, the stronger the emotional convergence between the two parties will be. The result will be elevated subordinate depersonalization and reduced personal accomplishment.

Due to their unique position within organizations, supervisors should have ample opportunities to express and transmit their burnout. Repeated exposure to and focus on burned out superiors' free expressions should lead to subordinate burnout. Therefore, drawing on emotional contagion theory, it is hypothesized:

Hypothesis 1a: Supervisor emotional exhaustion is positively related to subordinate emotional exhaustion.

Hypothesis 1b: Supervisor depersonalization is positively related to subordinate depersonalization.

Hypothesis 1c: Supervisor reduced personal accomplishment is positively related to subordinate reduced personal accomplishment.

\subsection{Susceptibility to Emotional Contagion}

Previous studies investigating the interaction between burnout and individual differences have been widely atheoretical (Bakker, Van Der Zee, Lewig, \& Dolland, 2006; Zellars, Perrewe, \& Hochwarter, 2000), failing to provide sufficient theoretical rationale for why and how the investigated individual difference variables should affect employee burnout. However, Hatfield et al.'s (1994) discussion includes a theoretical position on individual differences, which when applied to the study of burnout, acknowledges that subordinates with certain individual differences may operate as more effective receivers of burnout (they assume the senders' emotion).

Similarly, the interactional psychology framework articulates how personality influences one's perception of their environment and consequently their behavior (Schneider, 1983). If individual differences indeed are capable of explaining variation in how supervisor burnout affects subordinate burnout, the key question becomes which differences are most worthy of study. Drawing on the principles of emotional contagion theory, susceptibility to emotional contagion serves as an important individual difference which may affect subordinate burnout over time.

As discussed earlier, several studies have established empirical evidence for the emotional contagion phenomenon, indicating that individuals' in close relationships converge emotionally. Bakker and colleagues (2003; 2005) observed that teammates participating in a group project converged emotionally in such a way that the group itself became "burned-out." Research has indicated that these affective linkages among group members are in part attributable to the individual difference of susceptibility to emotional contagion (Doherty, 1997; Ilies, Wagner, \& Morgeson, 2007). Similarly, individual differences in susceptibility to emotional contagion should too contribute to the affective linkages between supervisors and subordinates.

Doherty (1997, p. 134) characterized one's susceptibility to the emotions of others as an individual difference variable that influences the extent to which "emotional stimuli elicit an emotional expression characteristic of the eliciting emotion." In the same way individuals may differ in their physical mannerisms (e.g. facial expressiveness), they are also likely to exhibit differences in susceptibility to emotional contagion. 
A range of factors influence individual differences in susceptibility to emotional contagion (Doherty, 1997). Individuals are thought to respond to various emotions (e.g. anger) and that these reactions vary from one person to another. Susceptibility to emotional contagion influences the extent to which people are affected by the others' emotional expressions. If a subordinate is highly susceptible to emotional contagion, then he or she is likely to automatically and closely mimic the emotionally laden physical expressions of others (i.e. emotional exhaustion) and listen to another's description of his/her emotional experience, remember similar experiences and feelings, and through this re-experiencing generate a similar emotional response (i.e. depersonalization and reduced personal accomplishment; Deutsch \& Madle, 1975). This discussion suggests then that subordinate susceptibility to emotional contagion will influence emotional convergence such that subordinates high on susceptibility will experience elevated levels of emotional exhaustion, depersonalization, and reduced personal accomplishment as transferred by their supervisor. These experiences are more salient for subordinates highly susceptible to emotional contagion leading to greater emotional convergence. This will result in a stronger positive relationship among burnout dimensions for subordinates highly susceptible to emotional contagion as compared with subordinates low on the dispositional difference. Therefore, drawing on emotional contagion theory, the interactional psychology framework, and the literature on susceptibility to emotional contagion, it is hypothesized:

Hypothesis 2a: Subordinate susceptibility to emotional contagion moderates the relationship between supervisor emotional exhaustion and subordinate emotional exhaustion, such that the positive relationship between supervisor emotional exhaustion and subordinate emotional exhaustion is stronger for subordinates high on susceptibility to emotional contagion compared to subordinates low on susceptibility to emotional contagion.

Hypothesis 2b: Subordinate susceptibility to emotional contagion moderates the relationship between supervisor depersonalization and subordinate depersonalization, such that the positive relationship between supervisor depersonalization and subordinate depersonalization is stronger for subordinates high on susceptibility to emotional contagion compared to subordinates low on susceptibility to emotional contagion.

Hypothesis 2c: Subordinate susceptibility to emotional contagion moderates the relationship between supervisor reduced personal accomplishment and subordinate reduced personal accomplishment, such that the positive relationship between supervisor reduced personal accomplishment and subordinate reduced personal accomplishment is stronger for subordinates high on susceptibility to emotional contagion compared to subordinates low on susceptibility to emotional contagion.

\section{Method}

Participants for this study were drawn from a mental health services organization employing approximately 630 total personnel (of which 145 served in a supervisory capacity), located in Southeastern United States. Overall, respondents from this organization were, on average, 38.45 years of age, had worked in their current organization for 7.86 years, had worked for their present immediate supervisor for 3.98 years, and were $66 \%$ female ( $44 \%$ male).

The primary source of data for this study was collected through employee opinion survey. Participants were guaranteed that their responses would be kept strictly confidential, and that under no circumstances would anyone inside the organization have access to their data or be able to individually identify them in any way.

Data for this study was collected at two time intervals. Each survey was administered online over a one week period during which all employees were solicited to participate. The survey at Time 1 was followed by a three month down period prior to the opening of the survey at Time 2. One week before the first survey link was sent, a "pre-notice" (Dillman, 2000) email was sent to all employees. This email came from the Director of Human Resources. This email briefly described the upcoming study (noting that its purposes were to better understand employee opinions and to help improve the quality of work life), encouraged employees to participate, and assured them that the data would go directly to the researcher and that the organization would not have access to individual responses. One week later, an email containing a link to the online survey was sent to all employees.

Data related to controls variables (i.e. age, gender, organizational tenure, and tenure with supervisor, role conflict, and role ambiguity), burnout (emotional exhaustion, depersonalization, and reduced personal accomplishment), and susceptibility to emotional contagion was collected at Time 1. Data related to burnout (emotional exhaustion, depersonalization, and reduced personal accomplishment) was collected again at Time 2 . A coding system was used to match supervisor and subordinate responses. The Direct of Human Resources confirmed all employees within this organization maintain "regular, daily face-to-face interaction" with their supervisor. 
A total of 252 employees responded to the survey administered at Time 1 ( $40 \%$ initial overall response rate). Of the respondents at Time 1, 117 of these respondents served in a supervisory capacity $(81 \%$ initial supervisor response rate) whereas 135 respondents did not serve in a supervisory capacity $(28 \%$ initial subordinate response rate. Of those who participated at Time 1, a total of 227 employees responded to and completed the remaining survey at Time 2 (36\% overall final response rate). Of these 227 respondents, 106 served in a supervisory capacity ( $73 \%$ final supervisor response rate) whereas 121 respondents did not serve in a supervisory capacity $(25 \%$ final subordinate response rate). These numbers represent a $11 \%$ overall respondent dropout rate from Time 1 to Time 2, a 9\% dropout rate for respondents who served in a supervisory capacity, and a 10\% drop out rate for respondents who did not serve in a supervisory capacity.

Of the final 106 supervisor respondents, 10 did not have any subordinates who completed both surveys at Time 1 and Time 2. Similarly, of the 121 subordinate respondents, 22 did not have a supervisor that completed both surveys at Time 1 and Time 2. Of the 96 supervisors that also had responding subordinates, 3 supervisors had more than 1 subordinate respondent. Because data was insufficient to aggregate to multiple levels, the 3 supervisors with more than 1 subordinate respondent and their subordinate respondents were removed from the analysis. Thus, a total of 93 supervisor-subordinate dyads (1 supervisor to 1 subordinate) served as the data sample for this study.

\subsection{Measures}

MBI. Employee burnout was measured using the Maslach Burnout Inventory (MBI; Maslach \& Jackson, 1981) consisting of twenty-two items and three original subscales. Emotional exhaustion subscale items included "I feel emotionally drained from my work" and "I feel fatigued when I get up in the morning and have to face another day on the job." Depersonalization subscale items included "I've become more callous toward people since I took this job" and "I worry that this job is hardening me emotionally". Reduced personal accomplishment subscale items included "I feel I'm positively influencing other people's lives through my work" and "I have accomplished many worthwhile things in this job." (It is important to note the positive anchoring of the reduced personal accomplishment scale: lower scores on this subscale indicate stronger feelings of reduced personal accomplishment whereas higher scores indicate weaker feelings of reduced personal accomplishment.) Items were assessed on a 7-point Likert scale $(1=$ Strongly Disagree to $7=$ Strongly Agree $)$. For supervisors, this measure demonstrated satisfactory reliability at Time 1 for emotional exhaustion $(\alpha=.90)$, depersonalization $(\alpha=.71)$, and reduced personal accomplishment $(\alpha=.83)$ and at Time 2 for emotional exhaustion $(\alpha=.92)$, depersonalization $(\alpha=.74)$, and reduced personal accomplishment $(\alpha=86)$, respectively. For subordinates, this measure demonstrated satisfactory reliability at Time 1 for emotional exhaustion $(\alpha=.89)$, depersonalization $(\alpha=.80)$, and reduced personal accomplishment $(\alpha=.80)$ and at Time 2 for emotional exhaustion $(\alpha=.93)$, depersonalization $(\alpha=.81)$, and reduced personal accomplishment $(\alpha=.71)$, respectively.

Susceptibility to Emotional Contagion. Susceptibility to emotional contagion was measured using Doherty's (1997) 15 item scale. Sample items included "If someone I'm talking with begins to cry, I get teary-eyed," "I tense when overhearing an angry quarrel," and "I notice myself getting tense when I'm around people who are stressed out." Items were assessed on a 5 -point Likert scale $(1=$ Never to $5=$ Always $)$. This measure demonstrated satisfactory reliability at Time $1(\alpha=.73)$.

Role Conflict. As a control variable, role conflict was measured using Peterson et al.'s (1995) 3 item scale. Sample items included "I often get involved in situations in which there are conflicting requirements," "I receive incompatible requests from two or more people," and "I have to do things that should be done differently under different conditions." Items were assessed on a 5-point Likert scale ( $1=$ Strongly Disagree to $5=$ Strongly Agree). This measure demonstrated satisfactory reliability at Time $1(\alpha=.82)$.

Role Ambiguity. As a control, role ambiguity was measured using Peterson et al.'s (1995) 5 item scale. Sample items included "I have clear planned goals and objectives for my job," "I know exactly what is expected of me," and "I know what my responsibilities are." Items were assessed on a 5-point Likert scale ( $1=$ Strongly Disagree to 5= Strongly Agree). It is important to note the positive anchoring of the role ambiguity scale: lower scores on this subscale indicate stronger feelings of role ambiguity whereas higher scores indicate weaker feelings of role ambiguity.) This measure demonstrated satisfactory reliability at Time $1(\alpha=.84)$.

\subsection{Controls}

Research studies suggest that gender differences in experienced burnout exist, however there appears to be mixed evidence pertaining to the pattern and complexity of relationships found (Lemkau, Rafferty, Purdy, \& Rudisill, 1987; Maslach \& Jackson, 1981, 1985; Pretty, McCarthy, \& Catano, 1992; Schwab \& Iwanicki, 1982). Burke (1989) found 
evidence that organizational tenure may influence the burnout process because more senior employees are more experienced in handling demands faced on the job. Similarly, Anderson and Iwanicki (1984) found experienced employees reported lower levels of burnout. Age has also been found to be associated with burnout as younger employees report higher levels of burnout than their older counterparts (e.g., Maslach \& Jackson, 1981, 1985; Perlman \& Hartman, 1982; Schwab \& Iwanicki, 1982). Additionally, studies investigating the causes of employee burnout have shown that environmental factors of the work setting (Pines \& Maslach, 1978; Maslach \& Pines, 1977) such as role conflict and role ambiguity are associated with elevated levels of burnout.

Based on these findings, employee gender, age, organizational tenure, role conflict, and role ambiguity as well as tenure with current supervisor were controlled for inasmuch as these variables may have be related to the independent and dependent variables examined in this study.

\section{Results}

Table 1 illustrates the means, standard deviations, and intercorrelations among all study variables. In the burnout literature it is common practice to denote emotional exhaustion as $E E$, depersonalization as $D P$, reduced personal accomplishment as RPA, and susceptibility to emotional contagion as $S E C$. These shorthand acronyms are utilized in some tables and figures where space does not allow use of the full term.

Table 1. Descriptive Statistics

\begin{tabular}{|c|c|c|c|c|c|c|c|c|c|c|c|c|c|c|c|}
\hline Variable & Mean & s.d. & 1 & 2 & 3 & 4 & 5 & 6 & 7 & 8 & 9 & 10 & 11 & 12 & 13 \\
\hline 2. Gender & .34 & .48 & .12 & - & & & & & & & & & & & \\
\hline 3. Organizational Tenure & 7.86 & 5.61 & $.46^{* *}$ & -.00 & - & & & & & & & & & & \\
\hline 5. Role Conflict & 3.28 & .86 & $-.20^{* *}$ & .05 & .08 & .06 & $(.82)$ & & & & & & & & \\
\hline 6. Role Ambiguity & 4.32 & .71 & $.14^{*}$ & $.32^{* *}$ & .01 & $.33^{* *}$ & $-.32 * *$ & $(.84)$ & & & & & & & \\
\hline 7. Susceptibility to Emotional Contagion & 3.70 & .58 & $-.16^{*}$ & .12 & -.03 & .13 & $.30^{* *}$ & .13 & $(.73)$ & & & & & & \\
\hline 10. Supervisor Reduced Personal Acc. ${ }^{1}$ & 5.71 & .88 & -.05 & .07 & .04 & .09 & .07 & .07 & .05 & -.07 & $.21^{* *}$ & $(.83)$ & & & \\
\hline 11. Subordinate Emotional Exhaustion ${ }^{2}$ & 3.65 & 1.40 & $-26^{* *}$ & -.09 & $.17^{*}$ & .02 & $.68^{* *}$ & $-.36^{* *}$ & $.20^{* *}$ & $.67^{* *}$ & $.41^{* *}$ & .03 & $(.93)$ & & \\
\hline 12. Subordinate Depersonalization ${ }^{2}$ & 2.61 & 1.11 & -.11 & -.06 & $.30^{* *}$ & $.17^{*}$ & $.50^{* *}$ & $-.35^{* *}$ & $.37 * *$ & $.50^{* *}$ & $.43^{* *}$ & .04 & $.66^{* *}$ & $(.81)$ & \\
\hline 13. Subordinate Reduced Personal Acc. ${ }^{2}$ & 5.87 & .91 & $.14^{*}$ & .30 & -.10 & -.02 & $-.16^{*}$ & $.19^{* *}$ & $.14^{*}$ & $-.40^{* *}$ & -.12 & $.22 *$ & $-.41^{* *}$ & -.09 & $(.71)$ \\
\hline
\end{tabular}

Scale reliabilities (Cronbach's alpha) are listed on the diagonal. $\mathrm{N}=186 .{ }^{1}$ at Time $1,{ }^{2}$ at Time 2.

$\dagger \mathrm{p} \leq .10, * \mathrm{p} \leq .05, * * \mathrm{p} \leq .01, * * * \mathrm{p} \leq .001$

Description: Descriptive Statistics and Correlations among Study Variables.

Hypotheses were tested using hierarchical linear regression analysis (see Table 2). Following Aiken and West (1991), predictors were centered before forming interaction terms. As shown in Table 2, control variables were entered in Step 1, followed by the appropriate supervisor burnout dimension at Time 1 in Step 2. Subordinate susceptibility to emotional contagion was entered in Step 3 to determine if it added any explained incremental variance over the appropriate supervisor burnout dimension at Time 1 and finally, the interaction between the appropriate supervisor burnout dimension at Time 1 and subordinate susceptibility to emotional contagion was entered in Step 4. Changes in R-Squared were evaluated to assess the predictive power of each model. 
Table 2. Hypotheses Results

\begin{tabular}{|c|c|c|c|c|c|c|c|c|c|c|c|c|}
\hline & \multicolumn{4}{|c|}{$\begin{array}{l}\text { Test of Hypothesis 2a: } \\
\text { Subordinate SEC moderates the } \\
\text { relationship between Supervisor EE and } \\
\text { Subordinate EE }\end{array}$} & \multicolumn{4}{|c|}{$\begin{array}{l}\text { Test of Hypothesis 2b: } \\
\text { Subordinate SEC moderates the } \\
\text { relationship between Supervisor DP } \\
\text { and Subordinate DP }\end{array}$} & \multicolumn{4}{|c|}{$\begin{array}{l}\text { Test of Hypothesis 2c: } \\
\text { Subordinate SEC moderates the } \\
\text { relationship between Supervisor DP and } \\
\text { Subordinate DP }\end{array}$} \\
\hline Predictors & $\begin{array}{c}\text { Step } \\
1\end{array}$ & $\begin{array}{c}\text { Step } \\
\mathbf{2}\end{array}$ & $\begin{array}{c}\text { Step } \\
\mathbf{3}\end{array}$ & $\begin{array}{c}\text { Step } \\
4\end{array}$ & $\begin{array}{c}\text { Step } \\
1\end{array}$ & $\begin{array}{c}\text { Step } \\
\mathbf{2}\end{array}$ & $\begin{array}{c}\text { Step } \\
\mathbf{3}\end{array}$ & $\begin{array}{c}\text { Step } \\
4\end{array}$ & $\begin{array}{c}\text { Step } \\
1\end{array}$ & $\begin{array}{c}\text { Step } \\
\mathbf{2}\end{array}$ & $\begin{array}{c}\text { Step } \\
\mathbf{3}\end{array}$ & $\begin{array}{c}\text { Step } \\
\mathbf{4}\end{array}$ \\
\hline Age & $-.23 * * *$ & $-.16^{* * *}$ & $-.16^{* *}$ & $-.15^{* * *}$ & $-.13^{* *}$ & -.08 & -.08 & -.08 & $.16^{* *}$ & $.20 * * *$ & $.20 * * *$ & $.20 * * *$ \\
\hline Gender & -.06 & -.02 & -.02 & -.01 & .04 & .05 & .05 & .05 & $.28 * * *$ & $.27 * * *$ & $.27 * * *$ & $.27 * * *$ \\
\hline Tenure w/ Supervisor & -.07 & $-.08+$ & -.08 & -.06 & $.15^{* *}$ & $.14^{* *}$ & $.14^{* *}$ & $.14 * *$ & .05 & .04 & .04 & .04 \\
\hline Organizational Tenure & $.25 * * *$ & .03 & .03 & .00 & $.29 * * *$ & $.25^{* * *}$ & $.24 * * *$ & $.24 * * *$ & $-.18 * *$ & $-.19^{* *}$ & $-.18^{* *}$ & $-.18^{* *}$ \\
\hline Role Conflict & $.59 * * *$ & $.49^{* * *}$ & $.49^{* * *}$ & $.50 * * *$ & $.35^{* * *}$ & $.15^{* *}$ & $.15^{* * *}$ & $.15^{* * *}$ & $-.12 \dagger$ & $-.23 * * *$ & $-.23 * * *$ & $-.23 * * *$ \\
\hline Role Ambiguity & $-.10^{\dagger}$ & $\begin{array}{c}.07 \\
50 * * *\end{array}$ & $\begin{array}{c}.07 \\
50 * * *\end{array}$ & $\begin{array}{c}.06 \\
98 * * *\end{array}$ & $-.28 * * *$ & $-.37 * * *$ & $-.37 * * *$ & $-.37 * * *$ & .03 & -.05 & -.05 & -.05 \\
\hline $\begin{array}{l}\text { Supervisor EE } \\
\text { Supervisor DP }{ }^{1}\end{array}$ & & $.50^{* * *}$ & $.50^{* * *}$ & $.98^{* * *}$ & & $.17 * * *$ & $.31 * * *$ & $.31 * * *$ & & & & \\
\hline Supervisor RPA ${ }^{1}$ & & & & & & & & & & $.21^{* *}$ & $.21 * *$ & $.23^{* *}$ \\
\hline SEC & & & -.03 & .16 & & & $.29 * *$ & $.35 * *$ & & & .02 & .03 \\
\hline SEC X Supervisor EE & & & & $.53 * *$ & & & & & & & & \\
\hline SEC X Supervisor DP & & & & & & & & $.19^{* * *}$ & & & & \\
\hline SEC X Supervisor RPA & & & & & & & & & & & & $.26^{* *}$ \\
\hline$\Delta R^{2}$ & .54 & .11 & .00 & .04 & .39 & .09 & .02 & .04 & .15 & .05 & .00 & .04 \\
\hline Total $R^{2}$ & .54 & .65 & .65 & .69 & .39 & .48 & .50 & .54 & .15 & .20 & .20 & .24 \\
\hline
\end{tabular}

Table values are standardized beta weights. ${ }^{1}$ at Time 1.

$\dagger \mathrm{p} \leq .10, * \mathrm{p} \leq .05, * * \mathrm{p} \leq .01, * * * \mathrm{p} \leq .001$

Description: Results of Hierarchical Linear Regression Tests of Main Effects and Moderation.

\subsection{Results for Control Variables}

As shown in Step 4 of Table 2, among control variables, age $(\beta==.15, \mathrm{p} \leq .001)$ and role conflict $(\beta=.49, \mathrm{p} \leq .001)$ were found to be related to subordinate emotional exhaustion. Tenure with supervisor $(\beta=.14, p \leq .05)$, organizational tenure $(\beta=.24, \mathrm{p} \leq .001)$, role conflict $(\beta=.15, \mathrm{p} \leq .001)$, and role ambiguity $(\beta=-.37, \mathrm{p} \leq .001)$ were found to be related to subordinate depersonalization. Lastly, age $(\beta=.20, p \leq .001)$, gender $(\beta=.27, p \leq .001)$, organizational tenure $(\beta=-.18, \mathrm{p} \leq .05)$, and role conflict $(\beta=-.23, \mathrm{p} \leq .001)$ were found to be related to subordinate reduced personal accomplishment.

\subsection{Results for Hypothesis $1 a$ \& $2 a$}

Hypothesis 1a was tested by regressing supervisor emotional exhaustion at Time 1 onto subordinate emotional exhaustion at Time 2 after entering the control variables in Step 1. Table 2 shows that, at Step 2 under the heading "Test of Hypothesis 2a," supervisor emotional exhaustion at Time 1 was positively related to subordinate emotional exhaustion at Time $2(\beta=.50, \mathrm{p} \leq .001)$ and accounted for 11 percent of the variance in the dependent variable. Accordingly, Hypothesis 1a was supported.

Hypothesis 2a was tested by regressing the interaction term between subordinate susceptibility to emotional contagion and supervisor emotional exhaustion at Time 1 onto subordinate emotional exhaustion at Time 2 following the control variables in Step 1, supervisor emotional exhaustion at Time 1 in Step 2, and subordinate susceptibility to emotional contagion in Step 3. Table 2 shows that, at Step 4 under the heading "Test of Hypothesis 2a," subordinate susceptibility to emotional contagion did moderate the relationship between supervisor emotional exhaustion at Time 1 and subordinate emotional exhaustion at Time $2(\beta=.53, \mathrm{p} \leq .001)$ and accounted for 4 percent of the variance in the dependent variable. This interaction, shown in Figure 2, indicates that for subordinates lower on susceptibility to 
emotional contagion, the line representing the relationship between subordinate emotional exhaustion at Time 1 and supervisor emotional exhaustion at Time 2 was positively sloped; however, for subordinates who were higher on susceptibility to emotional contagion the corresponding regression line was steeper. Accordingly, Hypothesis $2 \mathrm{a}$ was supported.

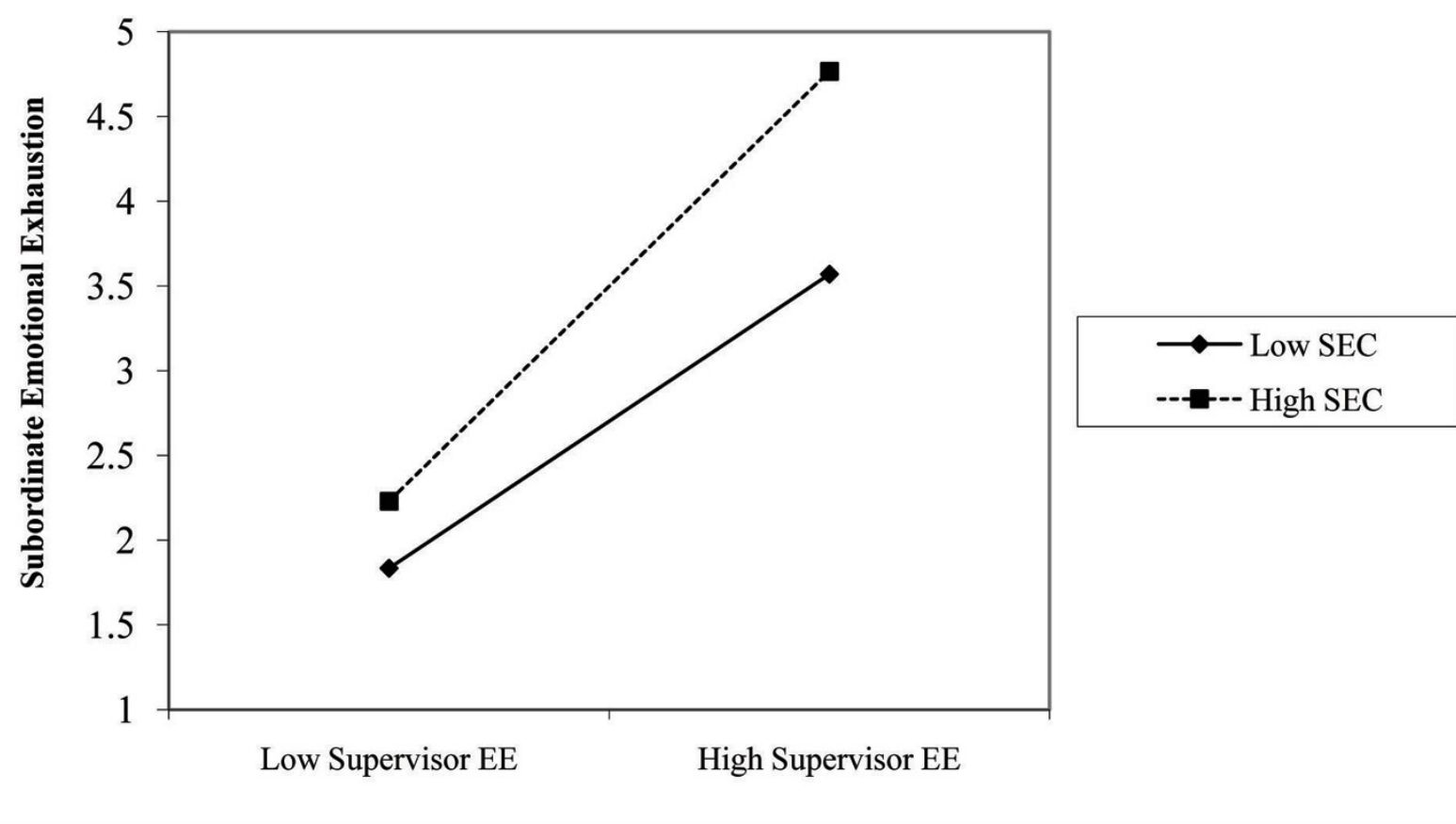

Figure 2. Subordinate Emotional Exhaustion

Description: Moderating Effect of Subordinate Susceptibility to Emotional Contagion on the Relationship Between Supervisor Emotional Exhaustion at Time 1 and Subordinate Emotional Exhaustion at Time 2.

\subsection{Results for Hypothesis $1 b \& 2 b$}

Hypothesis $1 \mathrm{~b}$ was tested by regressing supervisor depersonalization at Time 1 onto subordinate depersonalization at Time 2 after entering the control variables in Step 1. Table 2 shows that, at Step 2 under the heading "Test of Hypothesis $2 \mathrm{~b}$," supervisor depersonalization at Time 1 was positively related to subordinate depersonalization at Time $2(\beta=.17, \mathrm{p} \leq .001)$ and accounted for 9 percent of the variance in the dependent variable. Accordingly, Hypothesis $1 \mathrm{~b}$ was supported.

Hypothesis $2 \mathrm{~b}$ was tested by regressing the interaction term between subordinate susceptibility to emotional contagion and supervisor depersonalization at Time 1 onto subordinate depersonalization at Time 2 following the control variables in Step 1, supervisor depersonalization at Time 1 in Step 2, and subordinate susceptibility to emotional contagion in Step 3. Table 2 shows that, at Step 4 under the heading "Test of Hypothesis 2b," subordinate susceptibility to emotional contagion did moderate the relationship between supervisor depersonalization at Time 1 and subordinate depersonalization at Time $2(\beta=.19, \mathrm{p} \leq .001)$ and accounted for 4 percent of the variance in the dependent variable. This interaction, shown in Figure 3, indicates that for subordinates lower on susceptibility to emotional contagion, the line representing the relationship between subordinate depersonalization at Time 1 and supervisor depersonalization at Time 2 was positively sloped; however, for subordinates who were higher on susceptibility to emotional contagion the corresponding regression line was steeper. Accordingly, Hypothesis $2 \mathrm{~b}$ was supported. 


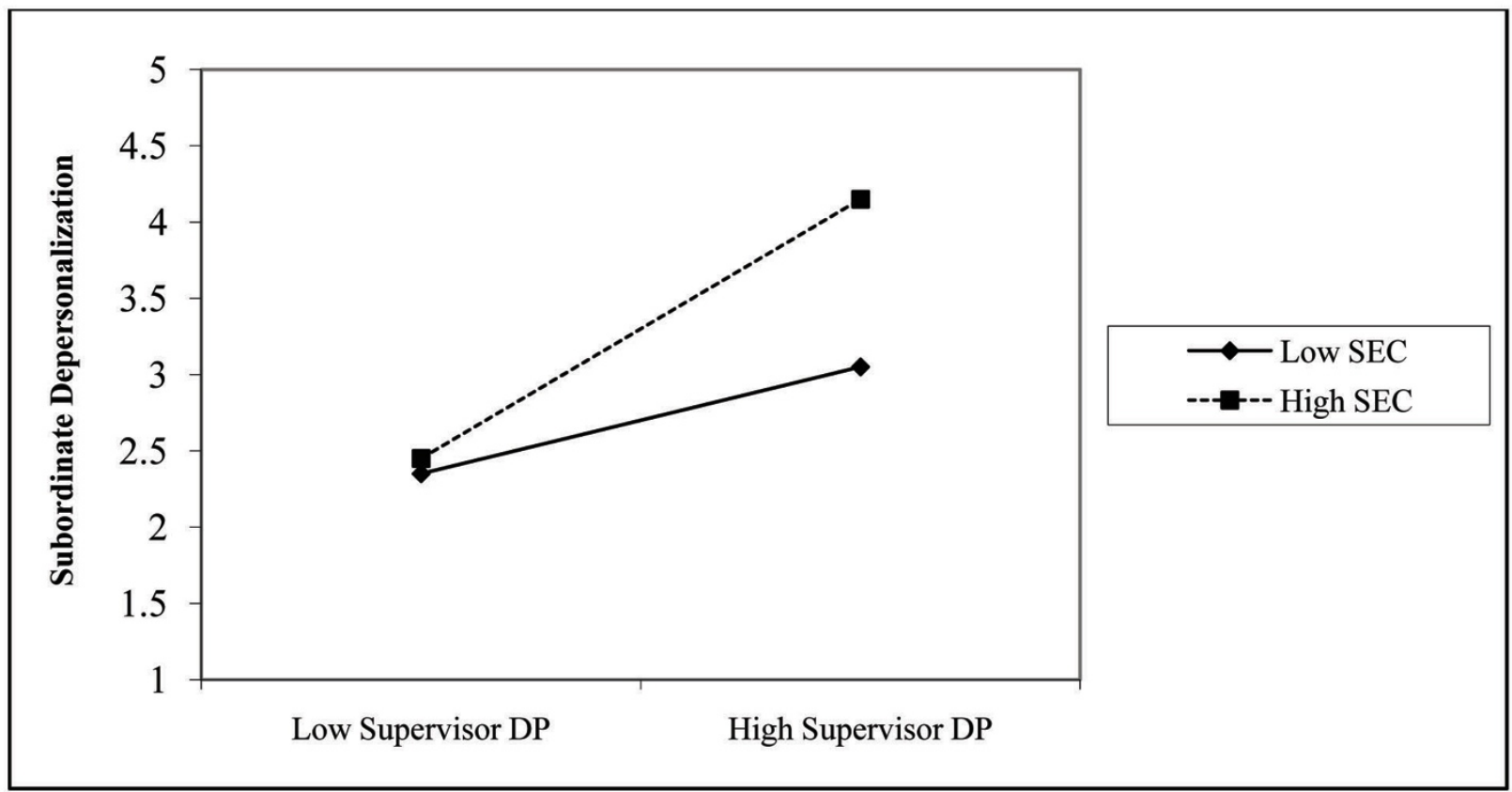

Figure 3. Subordinate Depersonalization

Description: Moderating Effect of Subordinate Susceptibility to Emotional Contagion on the Relationship Between Supervisor Depersonalization at Time 1 and Subordinate Depersonalization at Time 2.

\subsection{Results for Hypothesis $1 c$ \& $2 c$}

Hypothesis 1c was tested by regressing supervisor reduced personal accomplishment at Time 1 onto subordinate reduced personal accomplishment at Time 2 after entering the control variables in Step 1. Table 2 shows that, at Step 2 under the heading "Test of Hypothesis 2c," supervisor reduced personal accomplishment at Time 1 was positively related to subordinate reduced personal accomplishment at Time $2(\beta=.21, \mathrm{p} \leq .05)$ and accounted for 5 percent of the variance in the dependent variable. Accordingly, Hypothesis 1c was supported.

Hypothesis 2c was tested by regressing the interaction term between subordinate susceptibility to emotional contagion and supervisor reduced personal accomplishment at Time 1 onto subordinate reduced personal accomplishment at Time 2 following the control variables in Step 1, supervisor reduced personal accomplishment at Time 1 in Step 2, and subordinate susceptibility to emotional contagion in Step 3. Table 2 shows that, at Step 4 under the heading "Test of Hypothesis 2c," subordinate susceptibility to emotional contagion did moderate the relationship between supervisor reduced personal accomplishment at Time 1 and subordinate reduced personal accomplishment at Time $2(\beta=.26, \mathrm{p} \leq .05)$ and accounted for 4 percent of the variance in the dependent variable. This interaction, shown in Figure 4, indicates that for subordinates lower on susceptibility to emotional contagion, the line representing the relationship between subordinate reduced personal accomplishment and supervisor reduced personal accomplishment was negatively sloped; however, for subordinates who were higher on susceptibility to emotional contagion the corresponding regression line was positively sloped. As noted earlier, the positive anchoring of the reduced personal accomplishment scale is such that lower scores on this subscale indicate stronger feelings of reduced personal accomplishment whereas higher scores indicate weaker feelings of reduced personal accomplishment. Accordingly, Hypothesis 2c was supported. 


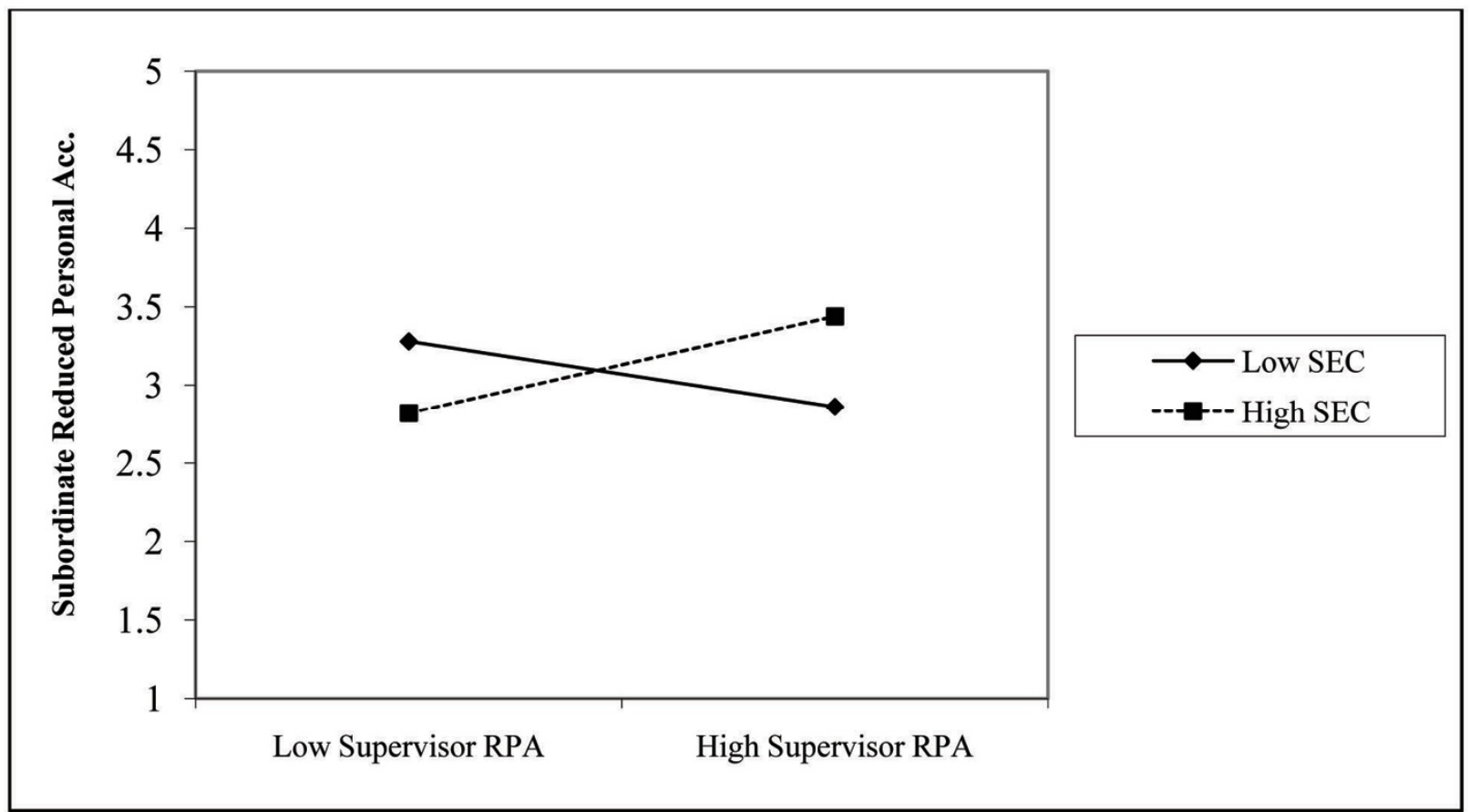

Figure 3. Subordinate Reduced Personal Accomplishment

Description: Moderating Effect of Subordinate Susceptibility to Emotional Contagion on the Relationship Between Supervisor Depersonalization at Time 1 and Subordinate Depersonalization at Time 2.

\subsection{Analysis of Change}

Using a repeated measures t-test, subordinate burnout at Time 1 was compared to subordinate burnout at Time 2 to determine if subordinate burnout increased in a statistically significant manner over the three-month period between Time 1 and Time 2. Burnout scores were indeed lower for subordinate emotional exhaustion at Time $1(\mathrm{M}=3.44)$ as contrasted with Time $2(\mathrm{M}=3.65)$ as indicated by a significant $\mathrm{t}$-test $(\mathrm{t}=2.66, \mathrm{p}=\leq .05)$, lower for subordinate depersonalization at Time $1(\mathrm{M}=2.30)$ as contrasted with Time $2(\mathrm{M}=2.61)$ as indicated by a significant $\mathrm{t}$-test $(\mathrm{t}=$ $2.66, \mathrm{p}=\leq .05)$, and higher for subordinate reduced personal accomplishment at Time $1(\mathrm{M}=5.98)$ as contrasted with Time $2(\mathrm{M}=5.87)$ as indicated by a significant $\mathrm{t}$-test $(\mathrm{t}=-3.86, \mathrm{p}=\leq .05)$, providing support that change occurred in the dependent variables over time purportedly due to supervisor burnout along these dimensions.

\section{Discussion}

\subsection{Implications for Theory, Research, and Practice}

Several theoretical implications may be drawn from this study's main analyses findings. First, this research study provides support that supervisor burnout plays an important role in the development of subordinate burnout. Although supervisors frequently experience affective states, the consequences of supervisors' affective states on their subordinates have remained unclear (Brief \& Weiss, 2002; Lewis, 2000). This study found that supervisor burnout increases experienced burnout in subordinates. Although noteworthy, these findings focus on the direct relationship between supervisor and subordinate burnout while disregarding potentially important intervening mechanisms. Indeed, scholars have postulated there are likely notable mediating variables through which supervisor mood and emotion affects subordinates. Commenting on the current state of the literature in this regard, Sy et al. (2005; P. 303) noted: "At this point, however, we cannot make definitive statements about the precise mechanisms that underlie the effects of the mood of the leader." Investigating mediating mechanisms may reveal a deeper understanding of the processes leading from supervisor to subordinate burnout.

Secondly, this study contributes to our knowledge concerning the emotional contagion process and burnout within a leadership context. Although the emotional contagion of various moods and emotions have received attention in the leadership domain (Cherulnik, Donley, Wiewel, \& Miller, 2001; Lewis, 2000; Sy et al., 2005), this study is the first to specifically address burnout. Results indicate that supervisors act as highly salient organizational members that transmit their burnout through emotional contagion to their subordinates. 
Furthermore, this study tested the effects of an important theoretically driven dispositional variable on the transfer of burnout from supervisor to subordinate: subordinate susceptibility to emotional contagion. Indeed, Buunk and Schaufeli (1993) contended that "burnout develops primarily in a social context, and that to understand the development and persistence of burnout, attention has to be paid to the way individuals perceive, interpret, and construct the behaviors of others at work" (pp. 52-53). This research study examined susceptibility to emotional contagion as a unidimensional construct comprising the extent to which people take on the emotions of others. Future research should explore emotional contagion as an individual difference variable from other perspectives. For example, Davis's (1983) discussion of dispositional empathy regards emotional contagion as comprising three distinct, but related dimensions. He suggests dispositional empathy reflects the extent to which an individual has warm, tender feelings of concern for another's wellbeing (empathic concern), can take another person's perspective (perspective taking), and experiences feelings of anxiety and discomfort in emotional social settings (personal distress). Considering emotional contagion from this perspective offers opportunity for richer discussion of individual differences and their effects on the contagion process.

Separately, practical implications may tentatively be drawn from this study's findings. First, supervisors must understand the role of their affective states in order to be successful. Through ongoing interaction, supervisors who regulate their affective states (e.g. emotional exhaustion) by revealing them or concealing them may cause change in their subordinates' affective states. It would be beneficial for supervisors to learn how to regulate their experiences and displays of burnout to subordinates to attain desired outcomes. This study's findings suggest that leaders who are inept at regulating their burnout could transmit these feelings to their subordinates over time. Enhancing supervisors' capability in regulation should result in minimizing emotional contagion that may hinder employee performance while facilitating emotional contagion that may improve employee performance during the relationship.

Second, these findings suggest that organizations can avert burnout before it becomes a debilitating condition by eliminating its prevalence at a key source: supervisors. Indeed, many researchers have contended that organizations should focus on preventing rather than treating burnout (van Dierendonck, Schaufeli, \& Buunk, 2001). Organizations should carefully monitor the pervasiveness of burnout among supervisors and proactively take steps to reduce and eliminate its occurrence. Organizations can directly assess burnout among supervisors through regular employee well-being surveys. Further, they can proactively reduce and eliminate burnout in supervisors by providing them with training in cognitive and behavioral strategies (see Schaufeli \& Enzmann, 1998, for an overview). By preventing the onset of burnout in supervisors, organizations can minimize its deleterious effects on the supervisor-subordinate relationship and stop the phenomenon from spreading over time from the upper echelons of management down into the day-to-day workforce before it ever starts.

\subsection{Limitations \& Suggestions for Future Research}

First, this study drew from a sample in mental health services industry. As the sample of organizations analyzed within this study is not representative of the population of organizations in the world at large, results may not be generalizable to other contexts. Results may only be generalized to the degree that the sample organization is representative of other similar organizations. Therefore, additional research is required using different samples from different areas of the world, in many different kinds of organizations, and in many different kinds of industries in order to increase the external validity of the results contained herein.

Second, this study is limited in that it focuses on the direction of burnout from supervisors to subordinates. However, it is indeed possible that subordinates may transfer their burnout to supervisors. In order to exclude this possibility, after applying appropriate controls subordinate emotional exhaustion, depersonalization, and reduced personal accomplishment at Time 1 were regressed onto supervisor emotional exhaustion, depersonalization, and reduced personal accomplishment at Time 2. However, results did provide support this idea for emotional exhaustion $(\beta=.23$, $\mathrm{p}>.05)$, depersonalization $(\beta=.17, \mathrm{p}>.05)$, and reduced personal accomplishment $(\beta=.13, \mathrm{p}>.05)$. Future studies should articulate and examine models of dyadic burnout wherein subordinate burnout affects supervisor burnout.

Lastly, this study examined relationships between supervisor burnout and subordinate burnout from a "dimension equivalence" perspective. For example, supervisor emotional exhaustion was hypothesized to be positively related to subordinate emotional exhaustion. However, supervisor emotional exhaustion was not specifically hypothesized to be positively related to subordinate depersonalization or reduced personal accomplishment. Theoretical models on the sequencing of the dimensions of burnout (e.g. emotional exhaustion occurs first, followed by depersonalization, followed by reduced personal accomplishment) have been conceptualized differently among various researchers throughout the years (see Cordes \& Douherty, 1993 for a review). Yet, these discussions are focused on explaining the sequencing of burnout within-individuals as opposed to between-individuals. Presently, the burnout literature 
lacks a cogent model of burnout that explicitly considers the sequencing of burnout in dyads (e.g. supervisor emotional exhaustion leads directly to subordinate depersonalization). Future research should consider theoretical perspectives that might inform the sequencing of burnout in the supervisor-subordinate relationship.

\subsection{Conclusion}

Findings indicate that supervisors play an important role in the development of burnout in their subordinates through the emotional contagion process and that employee susceptibility to emotional contagion acts as an important individual difference that impacts this process. If burnout trickles down from the upper echelons of the organizational hierarchy then it provides researchers the opportunity to identify useful samples for further study of the phenomenon and it allows organizations to identify its main source and engage in prevention strategies. If the burnout literature is to move forward, it must retrain its focus on research designs that properly test its theory.

\section{References}

Aiken, L. S., \& West, S. G. (1991). Multiple regression: Testing and interpreting interactions. Newbury Park: Sage

Anderson, M. B. G., \& Iwanicki, E. F. (1984). Teacher motivation and its relationship to burnout. Educational Administration Quarterly, 20, 109-132. http://dx.doi.org/10.1177/0013161X84020002007

Bakker, A.B., Demerouti, E., \& Schaufeli, W.B. (2003). The socially induced burnout model. In S.P. Shohov (Ed.), Advances in Psychology Research (Vol. 25). New York: Nova Science Publishers.

Bakker, A. B., Le Blanc, P. M., \& Schaufeli, W. B. (2005). Burnout contagion among nurses who work at intensive care units. Journal of Advanced Nursing, 51, 276-287. http://dx.doi.org/10.1111/j.1365-2648.2005.03494.x

Bakker, A. B., van der Zee, K. I., Lewig, K. A., Dollard, M. F. (2006). The Relationship Between the Big Five Personality Factors and Burnout: A Study Among Volunteer Counselors. Journal of Social Psychology, 146 (1), 31-50. http://dx.doi.org/10.1016/S2212-5671(13)00233-5

Burke, R. J. (1989). Toward a phase model of burnout: Some conceptual and methodological concerns. Group and Organization Studies, 14, 23-32. http://dx.doi.org/10.1177/105960118901400104

Chullen, C. L., Dunford, B. B., Angermeier, I., Boss, R. W., \& Boss, A. D. (2010). Minimizing deviant behavior in healthcare organizations: The effects of supportive leadership and job design. Journal of Healthcare Management, 55(6), 381-397.

Cherulnik, P. D., Donley, K. A.,Wiewel, T. S. R., \& Miller, S. R. (2001). Charisma is contagious: The effect of leaders' charisma on observers' affect. Journal of Applied Social Psychology, 31, 2149-2159. http://dx.doi.org/10.1111/j.1559-1816.2001.tb00167.x

Cordes C. L., \& Dougherty, T. W. (1993). A review and integration of research on job burnout. Academy of Management Review, 18, 621-656. http://dx.doi.org/10.5465/AMR.1993.9402210153

Connelly, S., Gaddis, B., \& Helton-Fauth, W. (2002). A closer look at the role of emotions in transformational and charismatic leadership. In B. J. Avolio \& F. J. Yammarino (Eds.), Transformational and charismatic leadership: The road ahead, Vol. 2. (pp. 255-283). Amsterdam: Elsevier.

Cropanzano, R., Rupp, D. E., \& Byrne, Z. S. (2003). The relationship of emotional exhaustion to work attitudes, job performance, and organizational citizenship behaviors. Journal of Applied Psychology, 88, 160-169. http://dx.doi.org/10.1037/0021-9010.88.1.160

Deutsch, F., \& Madle, R. (1975). Empathy: Historic and current conceptualizations, measurement, and a cognitive theoretical perspective. Human Development, 18, 267-287. http://dx.doi.org/10.1159/000271488

Dillman, D. A. (2000). Mail and Internet Surveys: The Tailored Design Method. New York: John Wiley.

Doherty, R. W. (1997). The Emotional Contagion Scale: A measure of individual differences. Journal of Nonverbal Behavior, 21,131-154. http://dx.doi.org/10.1023/A:1024956003661

George, J. M. (2000). Emotions and leadership: The role of emotional intelligence. Human Relations, 53, 1027http://dx.doi.org/1055. 10.1177/0018726700538001

Goleman, D., Boyatzis, R., \& McKee, A. (2001). Primal leadership: The hidden driver of great performance. Harvard Business Review, 79, 42-51.

Halbesleben, J. R. B., \& Bowler, W. M. (2007). Emotional exhaustion and job performance: The mediating role of motivation. Journal of Applied Psychology, 92, 93-106. http://dx.doi.org/10.1037/0021-9010.92.1.93 
Halverson, S. K., S. E. Murphy and R. E. Riggio (2004). 'Charismatic leadership in crisis situations: a laboratory investigation of stress and crisis', Small Group Research, 35, 495-514. http://dx.doi.org/10.1177/1046496404264178

Hatfield E., Cacioppo J.T. \& Rapson R.L. (1994). Emotional Contagion. Cambridge University Press, New York.

Ilies, R., Wagner, D. T., \& Morgesen, F. P (2007). Explaining affective linkages in teams: Individual differences in susceptibility to contagion and individualism-collectivism. Journal of Applied Psychology, 92, 1140-1148. http://dx.doi.org/10.1037/0021-9010.92.4.1140

Jackson, S. E., Schwab, R. L., \& Schuler, R. S. (1986). Toward an understanding of the burnout phenomenon. Journal of Applied Psychology, 71, 630-640. http://dx.doi.org/10.1037/0021-9010.71.4.630

Jackson, S. E., Turner, J. A., \& Brief, A. P. (1987). Correlates of burnout among public service lawyers. Journal of Occupational Behavior, 8, 339-349. http://dx.doi.org/10.1002/job.4030080406

Kahill, S. (1988). Symptoms of professional burnout: A review of the empirical evidence. Canadian Psychology, 29, 284-297. http://dx.doi.org/10.1037/h0079772

Lee, R. T., \& Ashforth, B. E. (1996). A meta-analytic examination of the correlates of the three dimensions of job burnout. Journal of Applied Psychology, 81, 123-133. http://dx.doi.org/10.1037/0021-9010.81.2.123

Leiter, M. P., \& Maslach, C. (1988). The impact of interpersonal environment on burnout and organizational commitment. Journal of Organizational Behavior, 9, 297-308. http://dx.doi.org/10.1002/job.4030090402

Maslach, C., Jackson, S. E., \& Leiter, M. P. (1996). The Maslach Burnout Inventory (3rd ed.). Palo Alto, CA: Consulting Psychologists Press.

Lemkau. J. P.. Rafferty, J. P., Purdy, R. R., \& Rudisill, J. R. (1967). Sex role stress and job burnout among family practice physicians. Journal of Vocational Behavior. 31, 81-90. http://dx.doi.org/10.1016/0001-8791(87)90036-4

Lewis, K. M. (2000). When leaders display emotion: how followers respond to negative emotional expression of male and female leaders. Journal of Organizational Behavior, 21, 221-234. http://dx.doi.org/10.1002/(SICI)1099-1379(200003)21:2<221::AID-JOB36>3.0.CO;2-0

Maslach, C. (1982). Burnout: The cost of caring. Englewood Cliffs, NJ: Prentice Hall.

Maslach, C. (1993). Burnout: A multidimensional perspective. In W.D. Schaufeli, C. Maslach, \& T. Marek (Eds.), Professional burnout: Recent developments in theory and research (pp. 19-32). Washington, D.C.: Taylor \& Francis.

Maslach, C., \& Jackson, S. E. (1981). The measurement of experienced burnout. Journal of Occupational Behaviour, 2, 99-113. http://dx.doi.org/10.1002/job.4030020205

Maslach, C., \& Jackson, S. E. (1985). The role of sex and family variables in burnout. Sex Roles, 12, 837-851. http://dx.doi.org/10.1007/BF00287876

Maslach, C., \& Pines, A. (1977). The burnout syndrome in the day care setting. Child Care Quarterly, 6, 100- 113. http://dx.doi.org/10.1007/BF01554696

Maslach, C., Schaufeli, W. B., \& Leiter, M. P. (2001). Job burnout. Annual Review of Psychology, 52, 397-422. http://dx.doi.org/10.1146/annurev.psych.52.1.397

Numerof, R. E. (1983). Managing stress: A guide for health professionals. Rockville, Md.: Aspen Systems Corporation.

Perlman, B., \& Hartman, E. A. (1982). Burnout: Summary and future research. Human Relations, 35, 283-305. http://dx.doi.org/10.1177/001872678203500402

Pines, A. M., Aronson, E., \& Kafry, D. (1981). Burnout: From tedium to personal growth. New York, NY: Free Press.

Pines, A., \& Maslach. C. (1978). Characteristics of staff burnout in mental health settings. Hospital and Community Psychiatry, 29, 233-237.

Peterson, M.F., Smith, P.B., Akande, A., Ayestaran, S., Bochner, S., Callan, V., et al. (1995). Role conflict, ambiguity, and overload: A 21-nation study. Academy of Management Journal, 38(2), 429-452. http://dx.doi.org/10.2307/256687 
Pretty, G. M. H., McCarthy, M. E., \& Catano, V. M. (1992). Psychological environments and burnout: Gender considerations within the corporation. Journal of Organizational Behavior, 13, 701-711. http://dx.doi.org/10.1002/job.4030130706

Schneider, B. (1983). Interactional psychology and organizational behavior. In L. L. Cummings \& B. M. Staw (Eds.), Research in organizational behavior 5, 1-31. Greenwich, CT: JAI Press.

Schaufeli, W. B., \& Enzmann, D. (1998). The burnout companion to study and research: A critical analysis. London: Taylor \& Francis.

Schwab, R. L., \& Iwanicki, E. F. (1982). Perceived role conflict, role ambiguity, and teacher burnout. Educational Administration Quarterly, 18, 60-74. http://dx.doi.org/10.1177/0013161X82018001005

Shirom, A. (1989). Burnout in work organizations. Chapter 2, pp 25-48. In C. L Cooper and I. Robertson (Eds.) International Review of Psychology, John Wiley and Sons.

Shirom, A., Westman, M., Shamai, O., \& Carel, R.S. (1997). Effects of work overload and burnout on cholesterol and triglycerides levels: The moderating effects of emotional reactivity among male and female employees. Journal of Occupational Health Psychology, 2, 275-288. http://dx.doi.org/10.1037/1076-8998.2.4.275

van Dierendonck, D., Schaufeli, W. B., \& Buunk, B. P. (2001). Burnout and Inequity Among Human Service Professionals: A Longitudinal Study. Journal of Occupational Health Psychology, 6 (1), 43-52. http://dx.doi.org/10.1037/1076-8998.6.1.43

Wolpin, J., Burke, R. J. \& Greenglass, E. R. (1991). Is job satisfaction an antecedent or a consequence of psychological burnout? Human Relations, 44, 193-209. http://dx.doi.org/10.1177/001872679104400205

Wright, T. A., \& Bonnett, D. G. (1997). The role of pleasantness and activation-based well-being in performance prediction. Journal of Occupational Health Psychology, 2, 212-219. http://dx.doi.org/10.1037/1076-8998.2.3.212

Wright, T. A., \& Hobfoll, S. E. (2004). Commitment, Psychological Well-Being, and Job Performance: An Examination of Conservation of Resources Theory and Job Burnout. Journal of Business and Management, 9 , 389-406.

Zellars, K. L., Perrewe, P. L., Hochwarter, W. A. (2000). Burnout in Health Care: The Role of the Five Factors of Personality. Journal of Applied Social Psychology, $30 \quad$ (8), $1570-1598$. http://dx.doi.org/10.1111/j.1559-1816.2000.tb02456.x 